\title{
Leukemoid reaction in a patient with acute lymphoblastic leukemia following the second chemotherapy
}

\section{Akut lenfoblastik lösemili hastada ikinci kemoterapi sonrası gelişen lökomoid reaksiyon}

\author{
Osman Yokuş ${ }^{1}$, Murat Albayrak ${ }^{2}$, Aynur Albayrak ${ }^{3}$, Habip Gedik ${ }^{4}$
}

\section{To the Editor,}

The occurrence of persistent neutrophilic leukocytosis above 50,000 cells/ $\mu \mathrm{L}$ for reasons other than leukemia is defined as leukemoid reaction. Chronic myelogenous leukemia (CML) and chronic neutrophilic leukemia (CNL) should be excluded, and underlying diseases or causes should be examined, in differential diagnosis. The most commonly observed causes of leukemoid reactions are severe infections, intoxications, malignancies, severe hemorrhage, or acute hemolysis [1]. J Clin Exp Invest 2013; 4 (2): 262-263

Rarely, leukemoid reaction can be seen in patients with acute leukemia subsequent to chemotherapy, as seen in our patient with acute lymphoblastic leukemia subsequent to pancytopenia due to chemotherapy $[2,3]$. A complete blood count of the patient was recovered subsequent to the development of leukemoid reaction.

The patient with precursor B cell acute lymphoblastic leukemia (fig.1) was treated with Standard hyper CVAD1 (Cyclophosphamide and mesna: 2x300 mg/m²/day (D), D1-3; Doxorubicine $50 \mathrm{mg} /$ $\mathrm{m}^{2} /$ day, D4; Vincristine $1,4 \mathrm{mg} / \mathrm{m}^{2} /$ day, D4 and D11; Dexamethasone $40 \mathrm{mg} /$ day, D1-4 and D11-14) and then CVAD2 regimen (Methotrexate $1 \mathrm{gr} / \mathrm{m}^{2} / \mathrm{day}$, D1; Cytosine arabinoside $2 \times 3 \mathrm{gr} / \mathrm{m}^{2} /$ day, D2-3 and Calcium folinate, first dose $50 \mathrm{mg}$ after six hours 15 $\mathrm{mg} /$ dose every six hours, for a total of 8 doses) as second chemotherapy. None of the chemotherapy regimens included G-CSF. On the twentieth day of the second chemotherapy, the leukocyte count rose to 50.000 cells $/ \mu \mathrm{L}$. The examined peripheral blood smear appeared as similar to the chronic phase of CML (fig.2). A cytogenetic examination of Philadelphia chromosome [t(9:22] was found to be negative, therefore, CML was excluded in the patient. Hydroxurea was initiated once a day. Leukocytosis recovered to normal range after one week (fig.3) and bone marrow examination revealed remission. Cytogenetic analysis was normal and this leukocytosis was determined as reactive leukemoid reaction. We aimed to report this case owing to the fact that leukocytosis associated with G-CSF, which is used to increase the leukocyte count during neutropenia, has been reported previously but it occurred after second chemotherapy without G-CSF [4]. We know that this condition is a very rare situation.

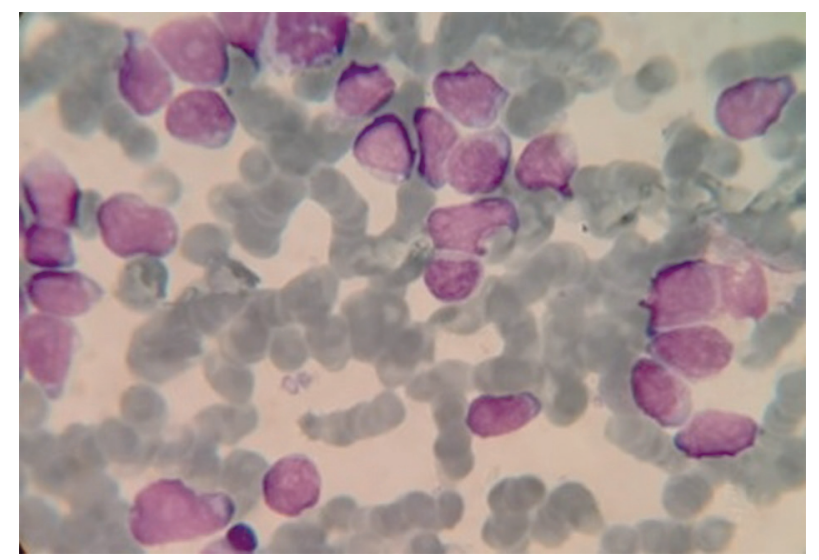

Figure 1. Bone marrow examination of patient with acute lymphoblastic leukemia (diffuse blastic infiltration)

${ }^{1}$ Okmeydanı Education and Research Hospital, Department of Hematology, Istanbul, Turkey

2 Dışkapı Yıldırım Beyazıt Education and Research Hospital, Department of Hematology, Ankara, Turkey

${ }^{3}$ Dışkapı Yıldırım Beyazıt Education and Research Hospital, Department of Pathology, Ankara, Turkey

${ }^{4}$ Okmeydanı Education and Research Hospital, Clinical Microbiology and Infectious Diseases, Istanbul, Turkey

Correspondence: Murat Albayrak,

Yeni Etlik Cad. Meltem sok. Turkuvaz apt. No:8/14 Etlik-Keçiören Ankara, Türkiye Email: muratalbayrak71@yahoo.com Received: 12.02.2013, Accepted: 28.03.2013

Copyright (C) JCEI / Journal of Clinical and Experimental Investigations 2013, All rights reserved 


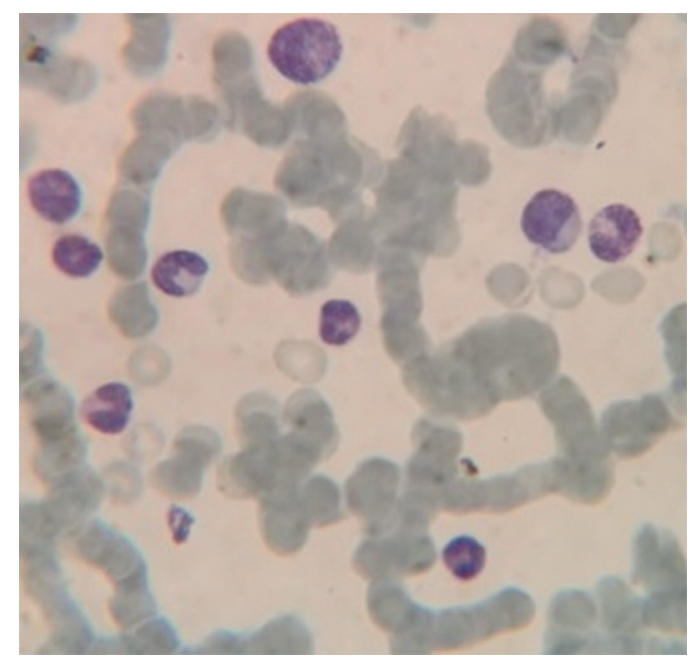

Figüre 2. Peripheral blood smear similar to chronic phase myeloid leukemia

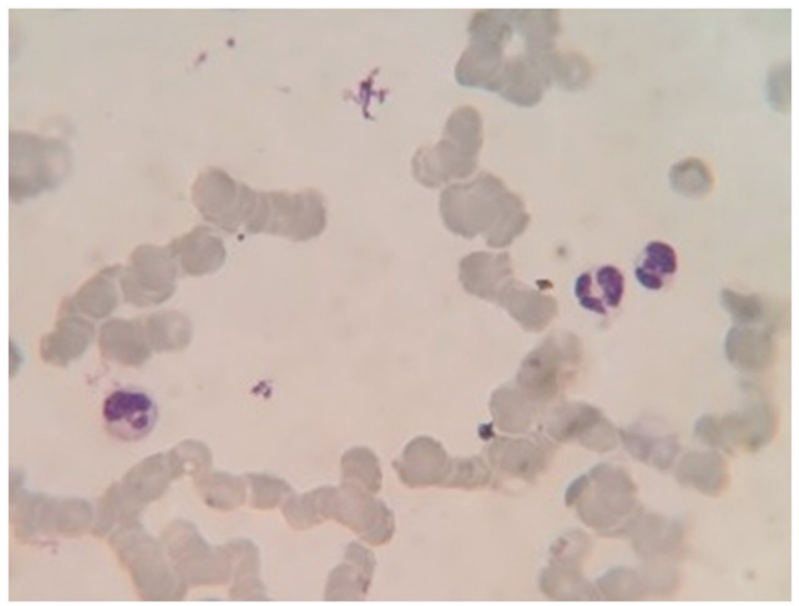

Figure 3. Peripheral blood smear was return to normal appearance after treatment of hydroxyurea

CML and leukemoid pictures tend to be confused. Therefore, these two almost identical conditions must be distinguished through a histological evaluation of bone biopsy and immunochemical staining $[5,6]$. It has been reported that in a case with systemic lupus erythrosis, deep myelosuppression occurred due to low dose methotrexate administered for arthritis, and leukemoid reaction developed after the drug was discontinued [7]. The fact that leukemoid reaction may occur due to G-CSF- producing tumors, and the said picture could remit with treatment of the tumor, was demonstrated [8].

Consequently, the development of leukocytosis due to leukemoid reaction subsequent to chemotherapy without G-CSF in patients with acute leukemia should be kept in mind during the treatment of leukemia. Written, informed consent was obtained from the patient.

\section{Conflict of interest statement}

The authors of this paper have no conflicts of interest, including specific financial interests, relationships, and/or affiliations relevant to the subject matter or materials included.

\section{REFERENCES}

1. Sakka V, Tsiodras S, Giamarellos-Bourboulis EJ, Giamarellou $\mathrm{H}$. An update on the etiology and diagnostic evaluation of a leukemoid reaction. Eur J Intern Med 2006;17:394-398.

2. Olipitz W, Strunk D, Beham-Schmid C, Sill H. Neutrophilic leukemoid reaction as the presenting feature of de novo and therapy-related acute leukemias. Acta Haematol 2004;111:233-234.

3. Kaung DT. Leukemoid reaction in acute lymphoblastic leukemia: a response to chemotherapy. J lowa Med Soc 1973;63:114-117.

4. Liu CZ, Persad R, Inghirami G, et al. Transient atypical monocytosis mimic acute myelomonocytic leukemia in post-chemotherapy patients receiving G-CSF: report of two cases. Clin Lab Haematol 2004;26:359362.

5. Schmid C, Frisch B, Beham A, et al. Comparison of bone marrow histology in early chronic granulocytic leukemia and in leukemoid reaction. Eur $\mathrm{J}$ Haematol 1990;44:154-158.

6. Florena AM, Franco V, Iannitto E, Salvato M. [Immunophenotyping of early-phase chronic myeloid leukemia and leukemoid reaction]. Pathologica 1994;86:384391.

7. Sun CY, Lin HC, Chen YC, et al. Leukemoid reaction after methotrexate-induced pancytopenia in a patient undergoing continuous ambulatory peritoneal dialysis. Chang Gung Med J 2006;29:513-517.

8. Mori H, Shibuya T, Osada T, et al. Response to chemotherapy in a case of gastric adenocarcinoma producing granulocyte colony-stimulating factor. Med Sci Monit 2010;16:CS119-123. 